\title{
OS NÍVEIS DE STRESS DOS ALUNOS DE LICENCIATURA, DA UCP - VISEU
}

\author{
Bruno Costa*, Fábio Lopes*, Mauro Neves*, Paulo Almeida Pereira †
}

Com este trabalho, realizado no ano lectivo de 2007/2008, pretende analisar-se os níveis de stress na comunidade académica da UCP Viseu, bem como as estratégias de coping desenvolvidas para o combater, temática que pode contribuir para a compreensão da forma como os alunos respondem às mudanças, nesta fase da sua vida, repleta de novos desafios e incertezas, que podem estar na origem de desequilíbrios emocionais e no esgotamento dos estudantes.

São apresentadas definições dos conceitos de stress e estratégias de coping, abordando-se também as mudanças inerentes à transição para $o$ ensino superior e as tarefas que precisam de superar ao longo do ciclo de estudos.

Procede-se ao enquadramento metodológico do estudo, com a caracterização da população em estudo, método de selecção da amostra, apresentação de objectivos e hipóteses e do instrumento de recolha de informação.

A análise permite determinar os factores de stress e as estratégias de coping predominantes, bem como a sua relação com os cursos frequentados pelos alunos, o facto de estar no início ou fim do curso e as variáveis de caracterização sexo, idade e nível sócio-económico. Finalmente são determinadas as relações existentes entre o stress e respectivos factores e o coping e respectivas estratégias.

Palavras-chave: Stress, Coping, Ensino superior.

This work, conducted in the 2007/2008 school year, intends to examine the levels of stress in the academic community of the Portuguese Catholic University (UCP) - Viseu, as well as the coping strategies developed to fight it, a theme that can contribute to the understanding of how students respond to changes at this stage of his

\footnotetext{
* Licenciados em Serviço Social - Departamento de Economia, Gestão e Ciências Sociais - Pólo de Viseu do Centro Regional das Beiras da Universidade Católica Portuguesa

${ }^{\dagger}$ Prof. Auxiliar - Departamento de Economia, Gestão e Ciências Sociais - Pólo de Viseu do Centro Regional das Beiras da Universidade Católica Portuguesa. E-mail: ppereira@ crb.ucp.pt
} 
life, full of new challenges and uncertainties, which may be the cause of imbalances and emotional exhaustion of students.

Definitions of stress and coping strategies are presented, also addressing the changes in the transition to higher education and the tasks that need to overcome along the course.

The methodological framework of the study is presented, with the characterization of the studied population, method of sample selection, objectives and hypothesis presentation and the information-gathering tool used.

The analysis allows to determine the predominating stressors and coping strategies, as well as their relationship with the courses taken by students, being in the beginning or end of the course and the characterization variables sex, age and socio-economic level. Finally, the relationship between stress and related factors and coping and their strategies is determined.

Keywords: Stress, Coping, higher education.

\section{INTRODUÇÃO}

Da entrada para o Ensino Superior à conclusão do curso ocorrem muitas mudanças na vida dos jovens. É uma fase repleta de novos desafios e incertezas, que podem estar na origem de desequilíbrios emocionais e no esgotamento dos estudantes. Acontece que a ideia de sucesso marca cada vez mais as sociedades actuais e se há uma geração ou duas ter um curso superior dava garantias de empregabilidade e era sinónimo de estabilidade, hoje em dia não é assim. A crescente pressão do mercado de trabalho coloca cada vez maiores exigências de competitividade e produtividade aos estudantes.

A palavra stress, no seio académico, está associada a momentos de contrariedade: as desigualdades de desempenho, a autoavaliação dos alunos, as expectativas contrárias às suas experiências, os exames, a adaptação a um mundo diferente do ensino secundário, que implica mudanças sociais, culturais ou até mesmo psicológicas e físicas. O principal motivo deste trabalho é tentar perceber as situações de stress e quais as estratégias de coping utilizadas para melhorar a qualidade de vida dos alunos.

Ainda que o stress seja um tema alvo de alguns trabalhos de investigação (Compas, 1987; Folkman e Moskowitz, 2000), consideramos, em contexto académico, ser fundamental a abordagem ao tema numa perspectiva holística. A preocupação deste estudo não se pretende exclusivamente com o sucesso académico, mas com o bem-estar dos estudantes.

De acordo com alguns estudos (Folkman e Lazarus, 1985), verificou-se que os alunos universitários apresentaram emoções de ameaça e de desafio, dois dias antes dos exames, outros (Pereira et al, 2006; Ferraz e Pereira, 2002; Ferreira, 2006) apontam que os bons alunos têm maior motivação e usam estratégias de coping mais eficazes e que, pelo contrário, os alunos com menor rendimento recorrem a piores estratégias de coping. 
Sendo o objectivo deste estudo a medição e identificação das circunstâncias indutoras de stress e a verificação de estratégias de coping mais utilizadas pelos alunos universitários, este trabalho divide-se em duas partes: o enquadramento teórico e o estudo empírico.

O enquadramento teórico é composto pelas perspectivas de alguns autores, divididas em três partes principais: conceitos de stress e os factores de stress académico; conceitos de coping e estratégias que os universitários utilizam para lidar com agentes indutores de stress; análise de um factor importante na vida de um jovem estudante: a transição e a adaptação ao ensino superior.

A parte empírica desenvolveu-se mediante um estudo quantitativo de inquérito por questionário, com o recurso a dois instrumentos: "Identificação dos Factores de Stress em Estudantes Universitários" (Serra, 2002), que permitiu a medição dos níveis de stress e os principais factores de stress e a escala "Lidar com o Stress" (Serra et al, 1988), que possibilitou identificar as estratégias de coping dos estudantes universitários da amostra.

\section{STRESS E COPING}

\subsection{Stress: perspectivas teóricas.}

Segundo Serra (2002), o stress determina consequências preocupantes que podem lesar o bem-estar, a saúde física e mental do indivíduo e "representa a relação que se estabelece entre a carga sentida pelo ser humano e a resposta psicofisiológica que, perante a mesma, o indivíduo desencadeia" (Lazarus, 1999, citado por Serra, 2002, p.13).

O stress pode induzir uma condição de incentivo ou de desgaste, o que é pertinente no contexto de ensino superior em que, por exemplo, o stress pode ser um impulso para resolver problemas ou estudar para um exame, ou por outro lado, ter repercussões negativas que promovem o sofrimento e deterioram a qualidade de vida.

Podem distinguir-se três modelos utilizados na concepção e avaliação do stress: os que focam as causas, os que focam as consequências e os que focam o processo. Os primeiros designam-se por abordagem ambiental, uma vez que tratam o stress como uma característica do estímulo, como uma carga, focada nos acontecimentos ou experiências nocivas do meio ambiente. Os segundos constituem a abordagem biológica, focada nas alterações fisiológicas que ocorrem no sistema biológico quando é afectado por um estímulo ou carga excessiva ou nociva. A terceira abordagem é a abordagem psicológica, focada na interacção entre o indivíduo e o meio e na avaliação subjectiva do stress que é feita pelo indivíduo.

Hans Selye, que foi pioneiro no desenvolvimento do conceito de stress, designou-o como sendo a resposta fisiológica do organismo quando este é sujeito 
a estímulos negativos: "o stress é o resultado de qualquer exigência sobre um ser humano, seja o efeito mental ou somático" (Selye, 1991, p.22).

A grande mudança no paradigma do stress, de uma visão colectiva para uma visão mais individual, deveu-se, em parte, ao facto de se verificar que a estímulos semelhantes correspondiam reacções diferentes. Deste modo o conceito de stress evoluiu de uma explicação determinista para uma explicação interaccionista, surgindo um modelo multidimensional, possibilitando a introdução de várias variáveis que podem contribuir para uma melhor explicação dos factores envolvidos na mediação dos efeitos do stress: o Modelo Transaccional de Lazarus e Folkman (1985). Estes consideram que o stress psicológico é a avaliação que o indivíduo faz da sua relação com o ambiente na medida em que pode exceder os seus recursos e afectar o seu bem-estar.

Serra refere-se aos aspectos cognitivos numa perspectiva complementar à visão de Selye do seguinte modo: "O homem é um ser pensante, que se envolve em processos de avaliação. Como tal, embora desenvolva um estado de tensão quando sente uma carga excessiva, o processo não acaba aí, não fica estático. Há uma interacção de duplo sentido que se estabelece entre o indivíduo/meio ambiente e o meio ambiente/indivíduo que vai determinar as consequências e a evolução da resposta" (Serra, 1999, p.14).

Este modelo tem a designação de modelo transaccional porque defende que o stress não é consequência directa de determinado stressor, mas resulta da interacção entre esse agente e a percepção/avaliação que a pessoa faz desse mesmo agente, introduzindo assim a relação do stress com o estudo das estratégias de gestão do stress, ou seja, as estratégias de coping.

Segundo Serra, “(...) a percepção de controlo, o sentido de competência, e as expectativas de auto-eficácia estão interligados. Quando o indivíduo melhora as suas aptidões e recursos, tal facto ajuda-o a criar a percepção de controle sobre os acontecimentos. Quando se torna capaz de os aplicar e, ao fazê-lo, atenua os efeitos do stress, então está a melhorar o seu sentido de competência. Quando verifica que a mudança se opera através do seu próprio comportamento reforça as expectativas de auto-eficácia" (Serra, 1999, p.92).

O grau de confiança que as pessoas sentem na sua capacidade de dominar o ambiente ou, alternativamente, se sentem grande vulnerabilidade considerando o mundo como perigoso e hostil, afecta o modo como um acontecimento irá produzir uma avaliação de ameaça ou desafio.

\subsection{Factores de Stress.}

A compreensão de uma situação de stress implica que se considere, não apenas os factores de stress, mas também o processo de adaptação, a possibilidade de crise e o estado de recuperação. De um modo geral, numa situação de stress não intervém apenas um único factor mas sim um factor central e outros decorrentes daquele ou independentes mas concomitantes. 
Os factores de stress constituem uma pressão que perturba o indivíduo ou o sistema, desencadeando um estado de tensão e desequilíbrio e exigindo mudanças, as quais são essenciais para que novos estados de equilíbrio sejam alcançados.

Alguns dos stressores específicos a estas etapas de desenvolvimento estão associados à escola: a nível académico: a pressão para o sucesso e para a obtenção de bons resultados, o grande número de disciplinas, que exige competências de organização e gestão do estudo e origina uma grande carga de trabalho; ao nível da relação com os professores e com as regras da escola; e ao nível da relação entre pares: a aceitação pelos colegas, o medo de desagradar.

Assim sendo, factores como a ansiedade, a exigência dos professores, a relativa independência dos pais, as actividades extra curriculares excessivas, a transição de escola, de cidade, a transição socio-cultural, a pressão dos pais, entre muitos outros, poderão levar o estudante universitário a ter altos níveis de stress. Não podemos deixar de referir o factor que talvez seja o mais importante: a ansiedade inerente à avaliação do desempenho, seja ela contínua ou ligada à expectativa de eficácia em momentos de avaliação decisivos, como são as épocas de exames, as apresentações orais ou a defesa de trabalhos finais de licenciatura.

\subsection{Coping: perspectivas teóricas.}

O termo coping refere-se às estratégias que são utilizadas pelo ser humano para lidar com as ocorrências indutoras de stress. Segundo Vaz Serra (2002), estas estratégias "podem ser orientadas para a resolução do problema, para o controlo da emoção ou para aspectos do relacionamento com pessoas da rede social a que o indivíduo pertence."

Lazarus e Folkman (1984) definem o coping como um conjunto de comportamentos que controlam condições adversas: os esforços adaptativos dos indivíduos, ou seja, as estratégias que utilizam para lidar com agentes indutores de stress. Estas estratégias pretendem resolver, tolerar, reduzir ou minimizar as exigências da relação de stress, tornando-as mais favoráveis e assegurando o bemestar pessoal.

Fonseca refere que "(...) é através do processo de coping e da consequente elaboração e concretização de estratégias de coping, que as pessoas procuram lidar com situações internas problemáticas e/ou gerir as transacções entre elas mesmas e o ambiente, que se apresentem como desafiantes para o próprio. Para Lazarus e Folkman (1984), o processo de coping é simultaneamente emocional e cognitivo, por meio do qual o indivíduo faz uma série de julgamentos, acerca dos potenciais efeitos dos acontecimentos no seu bem-estar" (Fonseca, 2005, p.148).

O significado de coping eficaz sujeita-se a mudanças permanentes, sendo necessário examinar os acontecimentos psicológicos, numa perspectiva longitudinal e mais holística, da forma como as pessoas lidam com o stress como processo: o que pensam, o que querem, como querem, como sentem e agem no seu 
esforço, perante uma situação de adaptação ou para atingirem os seus objectivos diferenças intra e inter individuais (Lazarus, 2000).

De um ponto de vista global e seguindo o modelo conceptual do stress e processo de coping de Moos e Schaefer, indicado por Serra (2002) e utilizando-o para os estudantes universitários, as respostas perante o stress devem ser compreendidas considerando cinco aspectos: circunstâncias de vida indutoras de stress e recursos sociais do próprio estudante (saúde física, capacidade económica e relações com a sua rede íntima); aspectos socio-demográficos nos quais se incluem os recursos pessoais de coping (auto-confiança, aspirações pessoais, aptidões, entre outros); crises e transições de vida actuais (factores relativos a acontecimentos); avaliação cognitiva da circunstância, a saúde e o bem-estar.

\subsection{Estratégias de Coping.}

As respostas ou as estratégias, para lidar com o stress, são consideradas um factor mediador dos efeitos que os acontecimentos sociais podem ter sobre um indivíduo. Folkman e Lazarus (1985), citados por Serra (2002), indicam que as estratégias de coping podem ser orientadas para dois objectivos diferentes: a resolução de problemas e o controlo das emoções acompanhantes. No primeiro caso, o estudante orienta os seus esforços para resolver a situação causadora de stress, no outro, tenta diminuir o estado de tensão emocional que foi suscitado interiormente.

De acordo com o tipo específico de situação, assim as estratégias de coping poderão ser mais ou menos influenciadas. Estas não são uniformes e apresentam várias funções. As estratégias de coping têm uma função protectora, realizando-se essa função através de três perspectivas diferentes, esquematizadas por Serra (1988) da seguinte forma:

- pela eliminação ou modificação das condições que criam problemas;

- pelo controlo perceptivo do significado da experiência ou das suas consequências;

- pela manutenção, dentro de limites razoáveis, das consequências emocionais dos problemas.

Através da primeira estratégia, o indivíduo utiliza as acções que permitem a busca de informação para poder actuar, ou mesmo o confronto com aqueles que criam as dificuldades ou os problemas.

$\mathrm{Na}$ segunda estratégia, o controlo perceptivo pode ser reconhecido pela "neutralização da ameaça", em que são utilizadas comparações positivas do problema (por exemplo: "podia ser pior"), ou através da ignorância selectiva tornando trivial ou minimizando o significado das ocorrências. Poderá ainda utilizar como estratégia o evitamento positivo do problema.

$\mathrm{Na}$ terceira estratégia podemos dizer que o indivíduo não lida frontalmente com os problemas. Através de limiares permitidos, tende a reduzir os estados de 
tensão emocional, de maneira a que possa aguentar as consequências emocionais dos problemas.

Por sua vez, Lazarus e Folkman atribuem ao coping duas funções fundamentais: esforços que permitam lidar de forma adequada com situações indutoras de stress - coping focado no problema; regulação do estado emocional, por meio de esforços que permitem ao indivíduo pensar e agir de uma forma eficaz - coping focado na emoção.

Consideram-se duas estratégias de coping centradas no problema: coping confrontativo - consiste em desenvolver acções para modificar a situação; resolução planeada do problema - procura analisar-se a situação para chegar a soluções e depois adoptar a acção directa para resolver o problema.

Enunciam-se depois seis estratégias de coping centradas nas emoções: distanciamento - realização de esforços para nos afastarmos da situação ou criarmos uma visão mais positiva; fuga-evitamento - pensamento mágico sobre a situação ou acções para afastamento da situação; auto-controlo - tentativa de modelar os nossos sentimentos e acções em relação ao problema; aceitação da responsabilidade - reconhecer o nosso papel no problema, tentando simultaneamente resolver a situação; reavaliação positiva - tentar criar um significado positivo para a situação em termos de crescimento pessoal; procura de apoio social - tentar obter apoio informativo ou emocional.

Segundo Compas (1987), as estratégias de coping que o indivíduo adopta são influenciadas pelo processo de socialização e história pessoal de aprendizagem: nos adolescentes, considera importantes o auto-conceito, auto-eficácia, autocontrolo e auto-percepções, que poderão influenciar o stress e as estratégias de coping.

As influências culturais e, especificamente, a aprendizagem cultural dos sistemas de valores e crenças, podem levar a diferentes formas de acção. Os homens e mulheres utilizam também diferentes formas de lidar com o stress, podendo estes dados ser um indicador de que a aprendizagem de estratégias de coping é influenciada pela aprendizagem de papéis sociais (Serra, 1988).

Os estudantes universitários, para combater situações de stress, utilizam ou poderão utilizar variadíssimas técnicas ou estratégias de coping.

\subsection{Transição e adaptação ao ensino superior.}

No Ensino Superior, desde a entrada até à conclusão do curso, verificam-se mudanças na vida dos jovens. É uma fase plena de novos desafios e incertezas, que podem originar desequilíbrios emocionais e esgotamento.

A transição para o ensino superior é encarada com expectativa, como um desafio, exigindo que os jovens se confrontem com múltiplas e complexas tarefas e as superem, para que possam progredir e desenvolver-se. Por esta razão, a adaptação ao ensino superior pode ser encarada como um processo multidimensional e um potencial agente stressante. Segundo Ferraz e Pereira 
(2002), citados por Ferreira (2006), esta transição realça problemas que deverão ser encarados em três dimensões: questões ligadas ao auto-conceito, problemas pessoais (solidão, saudades de casa); problemas académicos; e os problemas financeiros e de gestão da casa. De acordo com Ferreira (2006), a adaptação nunca ocorre isoladamente, mas sim num organismo que tem uma determinada história de vida, diferentes formas de resposta, face aos mesmos acontecimentos de vida, diferenças essas acentuadas por factores biológicos, socio-culturais e económicos.

Um acontecimento pode criar, em diferentes momentos da vida de um indivíduo, diferentes níveis de stress, devido ao facto de estar relacionado com recursos de resistência e estratégias de coping que cada indíviduo possui. "As diferentes estratégias de coping que utilizamos para lidar com acontecimentos indutores de stress, traduzem-se também em respostas diferentes a esses mesmos acontecimentos, que podem ter um carácter mais ou menos adaptativo" (Ferreira, 2006).

A entrada no Ensino Superior é um período de aumento da autonomia e da liberdade do jovem, mas trata-se de uma época em que também aumenta o seu sentido de responsabilidade e a sua autodisciplina. O estudante tem que lidar com inúmeras tarefas que não lhe são familiares: a procura de quarto ou casa; a procura de emprego em part-time (se o necessitar); a gestão de dinheiro; o lidar com uma vida social diferente; as diferenças entre o ensino secundário e o ensino superior (na dimensão das turmas, na avaliação, no contacto com os professores).

\section{ENQUADRAMENTO METODOLÓGICO}

Este processo de investigação tem por objectivo encontrar respostas para questões de investigação: quais os níveis de stress na comunidade académica da UCP - Viseu, quais os factores causadores de stress e quais as estratégias de coping utilizadas para os combater.

\subsection{Objectivos}

Para a realização deste estudo empírico, definiram-se também objectivos específicos, relativamente à população alvo:

- determinar os factores causadores de stress na comunidade académica.

- verificar quais as estratégias de coping dos estudantes da UCP - Viseu, para combater as situações de stress;

- comparar os níveis de stress e estratégias de coping entre as quatro licenciaturas e entre os alunos do primeiro e último anos;

\subsection{Desenho da Investigação}

O presente estudo é descritivo, pois pretende descrever a população, por forma a compreender, explicar e fornecer informações sobre os conceitos em análise: o 
stress e o coping, mas também correlacional, pois pretende determinar-se a relação entre os dois construtos.

\subsection{População e Amostra}

A população em estudo são os alunos do primeiro ciclo de estudos do Pólo de Viseu da Universidade Católica Portuguesa, nomeadamente os do primeiro e último anos de cada curso de licenciatura. Sendo a amostra um subgrupo da população, seleccionado com o propósito de obter informações sobre as características dessa mesma população, o processo de amostragem é não probabilístico por conveniência, pois a amostra é constituída pelos alunos que se encontravam a frequentar as aulas no momento da aplicação dos questionários.

\subsection{Instrumentos de Recolha de Informação}

Para a mediação e percepção dos níveis de stress e das estratégias de coping dos estudantes universitários da amostra, foram utilizados os instrumentos "Identificação dos Factores de Stress em Estudantes Universitários" e "Lidar com o Stress", apresentados em Anexo, a cuja numeração das questões colocadas se faz referência nos quadros seguintes.

Utilizou-se o questionário "Identificação dos Factores de Stress em Estudantes Universitários", desenvolvido por Anabela Pereira e pela equipa do Gabinete de Apoio Psicopedagógico dos Serviços de Acção Social da Universidade de Coimbra (GAP_SASUC), em 2003, uma vez que se trata de um instrumento desenvolvido para a realidade Portuguesa, com a finalidade de identificar os principais factores de Stress do estudante universitário.

A escala deste questionário é do tipo Likert e varia entre 1 e 5 pontos, com 50 itens, sendo que quanto maior for a pontuação obtida, maior é o nível de Stress do inquirido. Os autores do questionário identificaram quatro factores como os principais indutores de Stress na vida académica, que intitularam: ansiedade aos exames/avaliações; auto-estima e bem-estar; ansiedade social e condições sócioeconómicas, apresentados no Quadro I.

\section{Quadro I}

Factores de Stress

\begin{tabular}{ll}
\hline Factores de Stress & Questões \\
\hline Ansiedade aos exames/avaliações & $1,5,6,7,13,14$, , 26 e 34 \\
Auto-estima e Bem-estar & $28,29,30,44,46,47,48$ e 50 \\
Ansiedade social & $20,23,39,40$ e 41 \\
Condições sócio-económicas & $18,19,43$ \\
\hline
\end{tabular}




\section{Quadro II}

Estratégias de coping

\begin{tabular}{|c|c|c|c|}
\hline Estratégias de coping & Questões & Estratégias de coping & Questões \\
\hline Coping activo & $5,25,47,58$ & Apoio na Religião & $7,18,48,60$ \\
\hline Planificação & $19,32,39,56$ & Focagem de Emoções & $3,17,28,46$ \\
\hline Supressão de actividades & $15,33,42,55$ & Negação & $6,27,40,57$ \\
\hline Inibição de coping & $10,22,41,49$ & Desinvestimento & \\
\hline Apoio Social Instrumental & $4,14,30,45$ & comportamental & $9,24,37,51$ \\
\hline Apoio Social Emocional & $11,23,34,52$ & Desinvestimento Mental & $2,16,31,43$ \\
\hline Reinterpretação Positiva & $1,29,38,59$ & Uso de álcool/drogas & $12,26,35,53$ \\
\hline Aceitação & $13,21,44,54$ & Humor & $8,20,36,50$ \\
\hline
\end{tabular}

A versão utilizada é constituída por 15 escalas com 4 itens cada, num total de 60 itens, cuja escala de resposta é de tipo Likert, em que 1 significa habitualmente não faço isto de todo e 4 corresponde a habitualmente faço muito isto. Os itens que pertencem a cada escala encontram-se discriminados no Quadro II.

Quanto ao nível de consistência interna, verificou-se um valor elevado para as duas escalas e para muitas das suas dimensões, como pode observar-se no Quadro III.

A análise de consistência interna revelou que o valor de $\alpha$ de Cronbach é bastante superior a 0,8 para ambas as escalas, o que indica uma boa consistência interna (Yaffe, 1999 e Garson, 2006).

\section{Quadro III}

Medida da Consistência Interna das Escalas e suas Dimensões

\begin{tabular}{lcc}
\hline \multicolumn{1}{c}{ Escala } & Alfa de & \\
& Cronbach & Itens \\
\hline Escala de Stress & $\mathbf{0 , 9 4 8}$ & $\mathbf{5 0}$ \\
Ansiedade & 0,827 & 8 \\
Auto-estima & 0,853 & 8 \\
Ansiedade & 0,795 & 5 \\
Condições & 0,694 & 3 \\
\hline \multicolumn{2}{c}{} \\
\hline Escala de COPE & $\mathbf{0 , 9 2 9}$ & $\mathbf{6 0}$ \\
\hline Coping activo & 0,705 & 4 \\
Planificação & 0,715 & 4 \\
Supreșão de actividades & 0,594 & 4 \\
Inibição de coping & 0,462 & 4 \\
\hline
\end{tabular}

\begin{tabular}{lcc}
\hline \multicolumn{1}{c}{ Escala } & $\begin{array}{c}\text { Alfa de } \\
\text { Cronbach }\end{array}$ & Itens \\
\hline Apoio Social Instrumental & 0,772 & 4 \\
Apoio Social Emocional & 0,760 & 4 \\
Reinterpretação Positiva & 0,599 & 4 \\
Aceitação & 0,839 & 4 \\
Apoio na Religião & 0,891 & 4 \\
Focagem de Emoções & 0,615 & 4 \\
Negação & 0,533 & 4 \\
Desinvest. comportamental & 0,688 & 4 \\
Desinvestimento Mental & 0,485 & 4 \\
Uso de álcool/ drogas & 0,925 & 4 \\
Humor & 0,839 & 4 \\
\hline
\end{tabular}

A maioria das dimensões apresenta valores superiores a 0,7 , sendo assim adequadas, embora algumas das dimensões do coping apresentem valores inferiores, sendo também utilizadas, com a consciência de que podem não ser totalmente adequadas para medir os construtos em análise. Assim sendo, ambas as escalas possuem boas características psicométricas para esta amostra.

As escalas e respectivas dimensões foram construídas a partir do cálculo da média dos itens que as constituem, convertidos em valores percentuais, em que $0 \%$ é o ponto mínimo possível e $100 \%$ corresponde ao ponto máximo possível da 
escala ou dimensão, o que permite obter resultados mais facilmente perceptíveis e interpretáveis.

\section{ANÁLISE E DISCUSSÃO DOS RESULTADOS}

A análise estatística dos dados foi realizada com recurso ao programa Statistical Package for the Social Sciences (SPSS) for Windows. As opções metodológicas utilizadas no decorrer da análise estão amplamente explicadas por Maroco (2003) e Pestana e Gageiro (2005).

\subsection{Caracterização da Amostra}

A amostra é constituída por 80 alunos dos quatro cursos de licenciatura existentes na UCP - Viseu: Arquitectura, Gestão, Medicina Dentária e Serviço Social. Os alunos inquiridos foram dos primeiro e último anos.

De acordo com a Tabela I, na amostra verifica-se uma maioria do sexo feminino: $59 \%$, equilíbrio entre os alunos do primeiro e do último ano e predominância do curso de serviço social $(41 \%)$, seguido de medicina dentária $(30 \%)$ e arquitectura (20\%), o curso de gestão é menos representado e tem apenas alunos do $1 .^{\circ}$ ano. Refira-se ainda que a idade varia entre 18 e 41 anos, com um valor médio de 23,0 anos e um desvio padrão de 5,2 anos.

\section{Tabela I}

Caracterização da amostra

\begin{tabular}{|c|c|c|c|c|c|}
\hline Sexo & $\mathbf{n}$ & $\%$ & Curso & $\mathbf{n}$ & $\%$ \\
\hline Feminino & 47 & 58.8 & Arquitectura & 16 & 20.0 \\
\hline Masculino & 33 & 41.3 & Gestão & 7 & 8.8 \\
\hline Ano & $\mathbf{n}$ & $\%$ & Medicina Dentária & 24 & 30.0 \\
\hline $1^{\circ}$ ano & 42 & 52.5 & Serviço Social & 33 & 41.3 \\
\hline Finalista & 38 & 47.5 & Total & 80 & 100 \\
\hline
\end{tabular}

Quanto à caracterização sócio-económica do agregado familiar, de acordo com a Tabela II, a maioria da amostra tem pais com ensino superior, seguido do ensino secundário. Complementando estes resultados, verifica-se também que os rendimentos ilíquidos do agregado familiar predominantes são superiores a $1500 €$ mensais. 
Tabela II

Classificação sócio-económica

\begin{tabular}{lcccc}
\hline & \multicolumn{2}{c}{ Do pai } & \multicolumn{2}{c}{ da mãe } \\
\hline \multicolumn{1}{c}{ Habilitações literárias } & N & \% & n & \% \\
\hline Ensino Primário $\left(1^{\boldsymbol{o}}\right.$ ao $4^{\boldsymbol{o}}$ ano $)$ & 15 & 18.8 & 13 & 16.5 \\
Ensino Básico $\left(5^{\circ}\right.$ ao $9^{\circ}$ ano $)$ & 12 & 15.0 & 17 & 21.5 \\
Ensino Secundário $\left(10^{\circ}\right.$ ao $12^{\text {o }}$ ano $)$ & 24 & 30.0 & 18 & 22.8 \\
Ensino Superior & 29 & 36.3 & 31 & 39.2 \\
\hline Total & $\mathbf{8 0}$ & $\mathbf{1 0 0}$ & $\mathbf{7 9}$ & $\mathbf{1 0 0}$ \\
\hline
\end{tabular}

\begin{tabular}{lcc}
\hline Rendimento do Agregado Familiar & n & \% \\
\hline O a $500 €$ & 2 & 2.7 \\
501€ a 1000€ & 16 & 21.9 \\
1001€ a $1500 €$ & 10 & 13.7 \\
Superior a $1500 €$ & 45 & 61.6 \\
\hline Total & $\mathbf{7 3}$ & $\mathbf{1 0 0}$ \\
\hline
\end{tabular}

\subsection{Escala de Stress}

As estatísticas para a escala de stress apresentam-se na tabela III. O valor médio da escala de stress é $46 \%$, inferior ao ponto médio da escala (50\%). O tipo de stress predominante é a ansiedade aos exames / avaliações, com um valor médio de $60 \%$, seguido pela auto-estima e bem estar e condições sócioeconómicas, com cerca de $49 \%$ e o valor mais baixo é para a ansiedade social, com 40\%; todas as percentagens reportam-se às escalas de medida. Portanto, podemos verificar a existência de stress, mas com níveis não muito elevados, embora para a ansiedade aos exames / avaliações e a auto-estima e bem estar os valores sejam superiores.

\section{Tabela III}

Estatísticas para a Escala de Stress e Respectivas Dimensões

\begin{tabular}{lccccccc}
\hline & & & Desvio & Coef. \\
& Nariação & Mínimo & Máximo \\
\hline Escala de Stress & 80 & 46.1 & 16.8 & $36 \%$ & 7 & 100 \\
\hline Ansiedade exames/avaliações & 80 & 60.1 & 19.7 & $33 \%$ & 0 & 100 \\
Auto-estima e Bem-estar & 80 & 49.4 & 22.6 & $46 \%$ & 0 & 100 \\
Ansiedade social & 80 & 39.7 & 22.9 & $58 \%$ & 0 & 100 \\
Condições sócio-económicas & 80 & 48.5 & 24.5 & $50 \%$ & 0 & 100 \\
\hline
\end{tabular}




\subsection{Escala de Coping}

As estatísticas para a escala de coping apresentam-se na tabela IV.

Tabela IV

Estatísticas para a Escala de Coping e Respectivas Dimensões

\begin{tabular}{lcccccc}
\hline & & & Desvio & Coef. & & \\
& Nédia & Padrão & Variação & Mínimo & Máximo \\
\hline Escala de Cope & 80 & 42.7 & 12.7 & $30 \%$ & 11 & 75 \\
\hline Coping activo & 80 & 53.5 & 20.9 & $39 \%$ & 8 & 92 \\
Planificação & 79 & 49.3 & 19.7 & $40 \%$ & 0 & 92 \\
Supressão de actividades & 79 & 45.1 & 19.1 & $42 \%$ & 0 & 83 \\
Inibição de coping & 80 & 46.2 & 17.0 & $37 \%$ & 8 & 83 \\
Apoio Social Instrumental & 80 & 51.8 & 21.9 & $42 \%$ & 0 & 100 \\
Apoio Social Emocional & 80 & 51.5 & 22.6 & $44 \%$ & 0 & 100 \\
Reinterpretação Positiva & 80 & 61.7 & 19.3 & $31 \%$ & 17 & 100 \\
Aceitação & 80 & 42.7 & 24.3 & $57 \%$ & 0 & 100 \\
Apoio na Religião & 80 & 32.6 & 30.3 & $93 \%$ & 0 & 92 \\
Focagem de Emoções & 80 & 47.4 & 20.0 & $42 \%$ & 0 & 92 \\
Negação & 80 & 33.4 & 20.4 & $61 \%$ & 0 & 83 \\
Desinvestim. comportamental & 80 & 26.0 & 19.6 & $75 \%$ & 0 & 75 \\
Desinvestimento Mental & 80 & 44.3 & 20.3 & $46 \%$ & 0 & 100 \\
Uso de álcool/ drogas & 80 & 16.7 & 25.1 & $150 \%$ & 0 & 100 \\
Humor & 80 & 39.7 & 26.7 & $67 \%$ & 0 & 100 \\
\hline
\end{tabular}

O valor médio da escala é $43 \%$, também inferior ao ponto médio da escala. A estratégia de coping predominante é a reinterpretação positiva, com um valor médio de $62 \%$, seguida das estratégias coping activo, apoio social instrumental, apoio social emocional, planificação, focagem de emoções, inibição de coping e supressão de actividades, com valores médios entre $45 \%$ e $53 \%$, depois seguem-se o desinvestimento mental, aceitação e humor, com valores médios entre $40 \%$ e 45\%. Menos utilizadas são a negação e apoio na religião, com uma média de cerca de $33 \%$ e ainda menos utilizadas são o desinvestimento comportamental, com uma média de $26 \%$ e o uso de álcool/ drogas, com um valor médio de $17 \%$. Note-se ainda a elevada dispersão de resultados para o apoio na religião e o uso de álcool/ drogas, que indicam maior variabilidade na sua utilização.

\subsection{Relação com as variáveis em estudo}

Em primeiro lugar, através da aplicação do teste de Kolmogorov-Smirnov, com a correcção de Lilliefors, verifica-se que as variáveis em estudo não cumprem o pressuposto da normalidade da distribuição dos seus valores, pelo que qualquer análise de inferência estatística tem que recorrer a testes não paramétricos: o teste de Kruskall-Wallis (KW), para mais de dois grupos e o teste de Mann-Whitney (MW), para dois grupos. Utiliza-se como referência o valor de 5\%, usual nas Ciências Sociais, para estabelecer a significância das diferenças, cuja análise será enfatizada e descrita com maior detalhe para aquelas que são estatisticamente significativas. 


\section{Curso}

Analisando o Gráfico I, verificam-se diferenças significativas na escala de stress $\left(\mathrm{KW}: \chi^{2}=13,959, \mathrm{p}=0,003\right)$, sendo os níveis de stress superiores para o curso de Arquitectura, seguidos pela Medicina Dentária e, depois, pelo Serviço Social, sendo inferiores para o curso de Gestão.

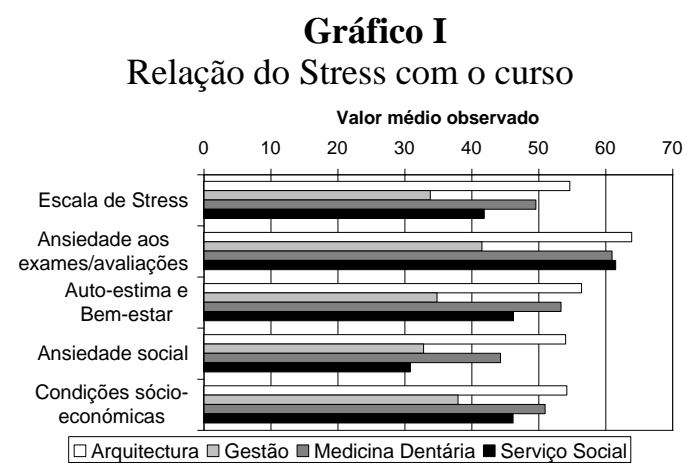

As diferenças também são significativas para a ansiedade face à avaliação $\left(\mathrm{KW}: \chi^{2}=8,306, \mathrm{p}=0,040\right)$, que, sendo idêntica para os restantes cursos, é inferior para o curso de gestão; e para a ansiedade social $\left(\mathrm{KW}: \chi^{2}=13,473, \mathrm{p}=0,004\right)$, superior para o curso de Arquitectura, intermédia para a Medicina Dentária e inferior para o Serviço Social e Gestão. Para os restantes factores de stress, existem também diferenças na amostra, mas não significativas.

O Gráfico II ilustra agora a relação entre os cursos e as estratégias de coping: genericamente, na amostra estas são superiores no curso de Medicina Dentária e inferiores para os restantes cursos, embora as diferenças não sejam significativas.

\section{Gráfico II}

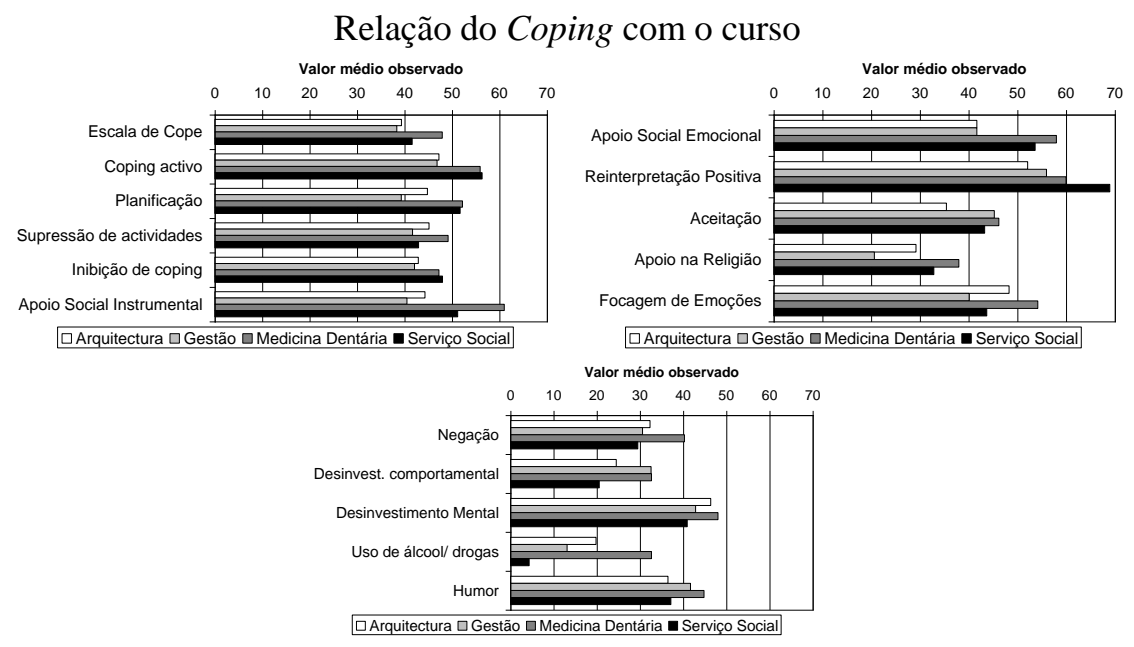


Para a maioria das estratégias, observam-se valores superiores na Medicina Dentária e no Serviço Social e inferiores nos outros dois cursos. Analisando aquelas que apresentam diferenças significativas entre os cursos: o apoio social instrumental $\left(\mathrm{KW}: \chi^{2}=7,896, \mathrm{p}=0,048\right)$ é superior para a Medicina Dentária e inferior para a Arquitectura e Gestão, a reinterpretação positiva $\left(\mathrm{KW}: \chi^{2}=10,224\right.$, $\mathrm{p}=0,017)$ é superior para o Serviço Social e inferior para a Gestão e, depois, para a Arquitectura e o uso de álcool/ drogas $\left(\mathrm{KW}: \chi^{2}=19,834\right.$, p <0,001) é superior para a Medicina Dentária e inferior para o Serviço Social.

\section{Ano do curso}

Genericamente, como ilustrado no Gráfico III, o stress e respectivos factores são superiores, na amostra, para o primeiro ano do curso, excepto para a ansiedade face à avaliação; no entanto, as diferenças nunca são estatisticamente significativas.

\section{Gráfico III}

Relação do Stress com o ano do curso

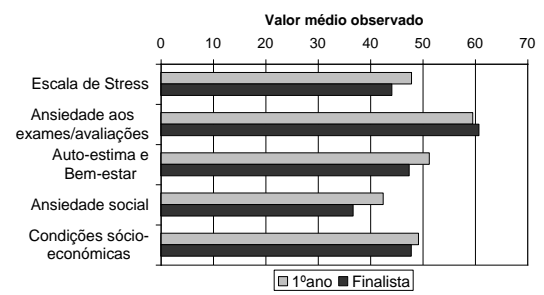

Podemos observar, no Gráfico IV que, genericamente, o coping é também superior, na amostra, para o primeiro ano do curso, embora especificamente algumas estratégias sejam mais utilizadas pelos alunos do primeiro ano e outras pelos alunos do último ano, não se verificando diferenças significativas, excepto para o uso de álcool/ drogas (MW: $\mathrm{U}=564,5, \mathrm{p}=0,010$ ), com uma incidência significativamente superior nos alunos do primeiro ano.

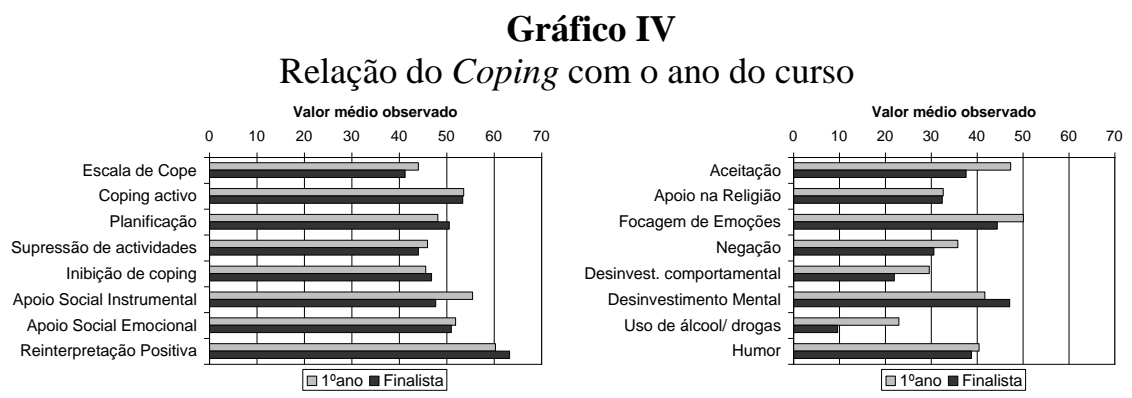


Dentro de cada curso, devido à reduzida dimensão das sub-amostras, não é possível estabelecer diferenças significativas, verificando-se genericamente o mesmo que se verifica para o total da amostra, tanto o stress, como as estratégias de coping, são superiores para os alunos do primeiro ano.

\section{Sexo}

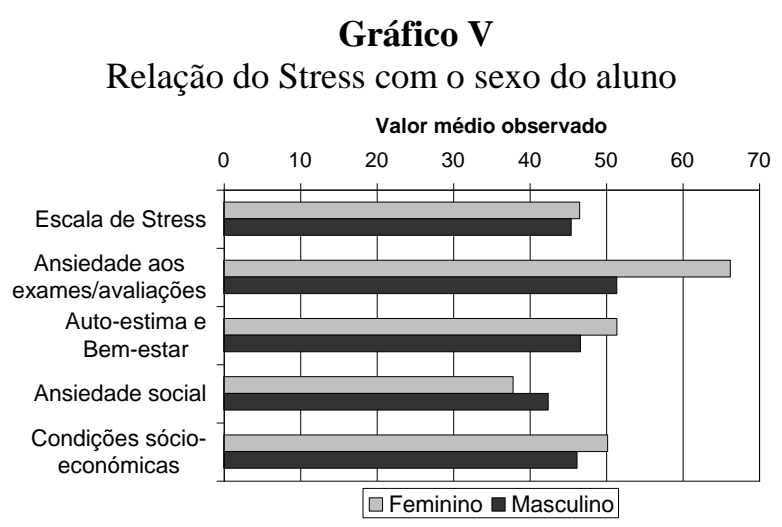

Genericamente, o stress é idêntico para ambos os sexos, mas especificamente a ansiedade face à avaliação, em que as diferenças são significativas (MW:U=441,0, $\mathrm{p}=0,001$ ), a auto-estima e bem-estar e as condições sócio-económicas são superiores para o sexo feminino, acontecendo o inverso com a ansiedade social.

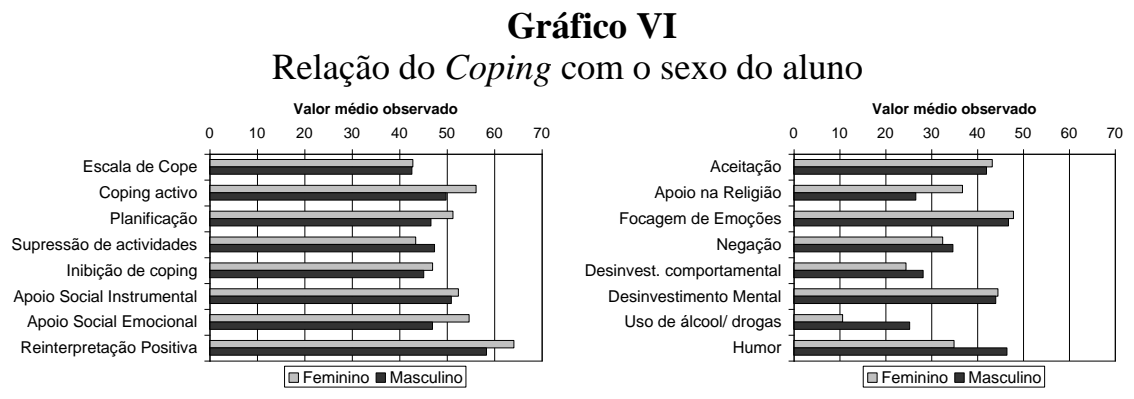

Genericamente, o coping é idêntico para ambos os sexos, no entanto, a maioria das estratégias são mais utilizadas pelo sexo feminino, com a excepção da supressão de actividades, negação e desinvestimento comportamental, mais utilizadas pelo sexo masculino, embora as diferenças não sejam significativas, e o uso de álcool/ drogas (MW:U=530,0, p=0,006) e o humor (MW:U=566,5, $\mathrm{p}=0,040)$, significativamente mais utilizadas pelo sexo masculino. 


\section{Nível sócio-económico}

A partir das habilitações académicas dos pais e dos rendimentos do agregado familiar, foram definidas três categorias sócio-económicas.

\section{Gráfico VII}

Relação do Stress com o nível sócio-económico do agregado familiar

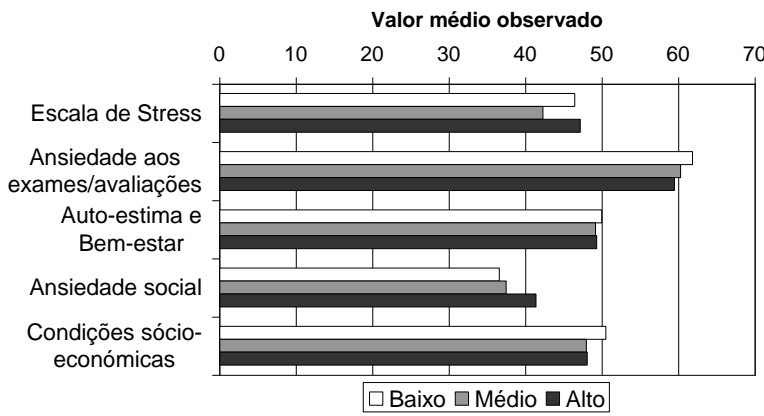

Genericamente, o stress é inferior para o nível sócio-económico intermédio, apresentando a ansiedade social valor superior para o nível alto, as condições sócio-económicas e ansiedade face às avaliações, valores superiores para o nível baixo, no entanto, nenhumas das diferenças observadas são significativas.

\section{Gráfico VIII}

Relação do Coping com o nível sócio-económico do agregado familiar
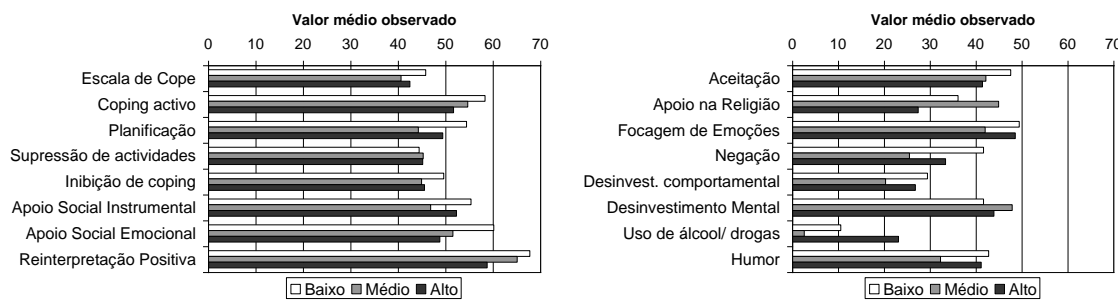

Genericamente, o coping e a grande maioria das respectivas estratégias são superiores para o nível sócio-económico mais baixo, excepto para o apoio na religião e o desinvestimento mental, superiores para o nível intermédio, no entanto, nenhuma destas diferenças são significativas, a excepção verifica-se mais uma vez para o uso de álcool/ drogas $\left(\mathrm{KW}: \chi^{2}=10,833, \mathrm{p}=0,004\right)$, significativamente mais utilizadas pelo nível sócio-económico mais alto e menos pelo nível intermédio. 


\section{Idade}

Utilizam-se coeficientes de correlação de Spearman, por não se cumprir o pressuposto da normalidade da distribuição das variáveis em estudo.

Para a escala de stress e respectivos factores, não se verificam relações significativas com a idade, excepto para a ansiedade social $(r=-0,232, p=0,039)$, que diminui significativamente com o aumento da idade. Para a escala de coping e a maioria das estratégias, tal também não se verifica, embora ocorram também excepções para as estratégias de apoio social instrumental $(r=-0,264, p=0,018)$ e uso de álcool/ drogas $(\mathrm{r}=-0,315, \mathrm{p}=0,004)$, cuja utilização diminui com o aumento da idade.

\subsection{Relação entre o stress e respectivos factores com o coping e respectivas estratégias}

A análise da relação entre o stress e seus factores com o coping e suas estratégias foi realizada, tal como no ponto anterior, através da determinação dos coeficientes de correlação de Spearman, cujos resultados se apresentam na Tabela $\mathrm{V}$, assinalando-se a negrito as relações estatisticamente significativas.

Em primeiro lugar, importa referir que, das estratégias de coping, o coping activo, a planificação, a supressão de actividades, o apoio social instrumental, o apoio social emocional, a aceitação e o humor não estão relacionadas de forma significativa com a escala de stress, nem com nenhum dos seus factores.

Genericamente, a escala de stress apresenta uma correlação positiva com a escala de coping, ou seja, os alunos que apresentam maiores níveis de stress, apresentam também mais estratégias de coping. Esta constatação, que se verifica também para as correlações significativas entre os factores de stress e as estratégias de coping leva-nos à conclusão de que estas surgem como uma reacção ao stress, quem apresenta maiores níveis de stress, tem a necessidade de utilizar mais estratégias de coping, ao contrário do que seria de esperar: que o coping provocasse uma diminuição dos níveis de stress.

Mais especificamente, a escala de coping está correlacionada positivamente com os factores de stress auto-estima e bem-estar e condições sócio-económicas, pelo que podemos concluir que, genericamente, o coping surge como resposta a estes dois factores de stress, não sendo uma reacção à ansiedade. A escala de stress está correlacionada positivamente com as estratégias de coping focagem de emoções, negação, desinvestimento comportamental e mental e uso de álcool/ drogas, pelo que podemos concluir que estas estratégias de coping são desenvolvidas devido ao stress.

Mais especificamente ainda, as estratégias inibição de coping e apoio na religião surgem como resposta ao factor de stress associado às condições sócioeconómicas; a focagem de emoções e desinvestimento mental são utilizadas para responder a todos os factores de stress; a negação correlaciona-se com a autoestima e bem-estar, ansiedade social e condições sócio-económicas; o 
desinvestimento comportamental está correlacionado com a auto-estima e bemestar e ansiedade social; e o uso de álcool/ drogas surge como resposta à ansiedade social. Apenas se verifica uma correlação negativa significativa, entre a reinterpretação negativa e a ansiedade social, ou seja esta estratégia de coping é inferior para quem tem mais ansiedade social.

Tabela V

Relação entre o Stress e o Coping

\begin{tabular}{|c|c|c|c|c|c|c|}
\hline & & $\begin{array}{c}\text { Escala } \\
\text { de Stress }\end{array}$ & $\begin{array}{l}\text { Ansiedade } \\
\text { face à } \\
\text { avaliações }\end{array}$ & $\begin{array}{c}\text { Auto- } \\
\text { estima e } \\
\text { Bem-estar }\end{array}$ & $\begin{array}{l}\text { Ansiedade } \\
\text { social }\end{array}$ & $\begin{array}{c}\text { Condições } \\
\text { sócio- } \\
\text { económicas }\end{array}$ \\
\hline \multirow[t]{2}{*}{ Escala de Cope } & $\mathrm{r}$ & $.260(*)$ & .145 & $.262(*)$ & .158 & $.314(* *)$ \\
\hline & $\mathrm{p}$ & .020 & .198 & .019 & .160 & .005 \\
\hline \multirow[t]{2}{*}{ Coping activo } & $\mathrm{r}$ & .044 & .066 & .118 & -.145 & .153 \\
\hline & $\mathrm{p}$ & .700 & .560 & .297 & .198 & .176 \\
\hline \multirow[t]{2}{*}{ Planificação } & $\mathrm{r}$ & .021 & .091 & .045 & -.077 & .057 \\
\hline & $\mathrm{p}$ & .852 & .426 & .694 & .500 & .621 \\
\hline \multirow{2}{*}{$\begin{array}{l}\text { Supressão de } \\
\text { actividades }\end{array}$} & $\mathrm{r}$ & .215 & .160 & .179 & .106 & .212 \\
\hline & $\mathrm{p}$ & .057 & .160 & .113 & .353 & .061 \\
\hline \multirow{2}{*}{$\begin{array}{l}\text { Inibição de } \\
\text { Coping }\end{array}$} & $\mathrm{r}$ & .185 & .180 & .179 & .050 & $.293(* *)$ \\
\hline & $\mathrm{p}$ & .101 & .111 & .112 & .662 & .008 \\
\hline \multirow{2}{*}{$\begin{array}{l}\text { Apoio Social } \\
\text { Instrumental }\end{array}$} & $r$ & .157 & .070 & .202 & -.032 & .138 \\
\hline & $\mathrm{p}$ & .165 & .536 & .072 & .777 & .221 \\
\hline \multirow{2}{*}{$\begin{array}{l}\text { Apoio Social } \\
\text { Emocional }\end{array}$} & $r$ & .061 & .135 & .134 & -.097 & .111 \\
\hline & $\mathrm{p}$ & .590 & .231 & .236 & .391 & .327 \\
\hline \multirow{2}{*}{$\begin{array}{l}\text { Reinterpretação } \\
\text { Positiva }\end{array}$} & $\mathrm{r}$ & -.098 & -.047 & -.041 & $-.240(*)$ & .178 \\
\hline & $\mathrm{p}$ & .387 & .676 & .717 & .032 & .115 \\
\hline \multirow[t]{2}{*}{ Aceitação } & $r$ & .084 & .033 & .073 & .093 & .123 \\
\hline & $\mathrm{p}$ & .460 & .774 & .521 & .410 & .279 \\
\hline \multirow{2}{*}{$\begin{array}{l}\text { Apoio na } \\
\text { Religião }\end{array}$} & $\mathrm{r}$ & .131 & .101 & .104 & .137 & $.228(*)$ \\
\hline & $\mathrm{p}$ & .247 & .372 & .361 & .226 & .042 \\
\hline \multirow{2}{*}{$\begin{array}{l}\text { Focagem de } \\
\text { Emoções }\end{array}$} & $r$ & $.429(* *)$ & $.320(* *)$ & $.410(* *)$ & $.354(* *)$ & $.335(* *)$ \\
\hline & $\mathrm{p}$ & .000 & .004 & .000 & .001 & .002 \\
\hline \multirow[t]{2}{*}{ Negação } & $\mathrm{r}$ & .331(**) & .108 & $.266(*)$ & $.431(* *)$ & $.244(*)$ \\
\hline & $\mathrm{p}$ & .003 & .339 & .017 & .000 & .029 \\
\hline \multirow{2}{*}{$\begin{array}{l}\text { Desinvest. } \\
\text { comportamental }\end{array}$} & $r$ & $.309(* *)$ & .071 & $.312(* *)$ & $.389(* *)$ & .192 \\
\hline & $\mathrm{p}$ & .005 & .529 & .005 & .000 & .089 \\
\hline \multirow{2}{*}{$\begin{array}{l}\text { Desinvestimento } \\
\text { Mental }\end{array}$} & $\mathrm{r}$ & $.279(*)$ & $.286(*)$ & $.263(*)$ & $.298(* *)$ & $.309(* *)$ \\
\hline & $\mathrm{p}$ & .012 & .010 & .019 & .007 & .005 \\
\hline \multirow{2}{*}{$\begin{array}{l}\text { Uso de álcool/ } \\
\text { Drogas }\end{array}$} & $r$ & $.240(*)$ & -.089 & .113 & $.284(*)$ & .148 \\
\hline & $\mathrm{p}$ & .032 & .430 & .320 & .011 & .190 \\
\hline \multirow[t]{2}{*}{ Humor } & $r$ & .154 & -.070 & .101 & .162 & .134 \\
\hline & $\mathrm{p}$ & .172 & .539 & .371 & .151 & .235 \\
\hline
\end{tabular}

\footnotetext{
** Correlação forte, para um nível de significância de 0.01 .
}

* Correlação normal, para um nível de significância de 0.05. 


\section{CONCLUSÃO}

O objectivo empírico deste estudo foi a medição e identificação das circunstâncias indutoras de stress e a verificação de estratégias de coping mais utilizadas pelos alunos de licenciatura, da UCP, em Viseu, para o que utilizámos duas escalas: "Identificação de factores de stress em estudantes universitários" e "Lidar com o Stress". Questionaram-se 80 alunos, dos primeiros e último anos, dos quatro cursos de licenciatura.

Os resultados obtidos indicam que existem níveis de stress moderados nesta comunidade estudantil, pois, em média, não ultrapassam o valor médio da escala de medida, sendo o factor de stress predominante a ansiedade aos exames / avaliações e o menos verificado a ansiedade social.

As estratégias de coping apresentam valores concordantes com os valores de stress, também abaixo do ponto médio da escala de medida, sendo a estratégia claramente predominante a reinterpretação positiva, seguida das estratégias coping activo, apoio social instrumental, apoio social emocional, planificação, focagem de emoções, inibição de coping e supressão de actividades. Menos utilizadas são a negação e apoio na religião e ainda menos o desinvestimento comportamental e o uso de álcool/ drogas.

Os níveis de stress são superiores para o curso de Arquitectura e inferiores para o curso de Gestão, apresentando os alunos de Medicina Dentária e Serviço Social valores intermédios. A mesma relação com os cursos verifica-se para a ansiedade face à avaliação.

Quanto às estratégias de coping, genericamente estas são superiores no curso de Medicina Dentária e inferiores para os restantes cursos, embora sem diferenças significativas. Na maioria das estratégias, observam-se valores superiores na Medicina Dentária e no Serviço Social, sendo as diferenças significativas para o apoio social instrumental, superior para a Medicina Dentária e inferior para a Arquitectura e Gestão; para a reinterpretação positiva, superior para o Serviço Social e inferior para a Gestão; e o uso de álcool/ drogas, superior para a Medicina Dentária e inferior para o Serviço Social.

Normalmente, o stress e respectivos factores são superiores para o primeiro ano do curso, embora de forma não significativa, isto pode dever-se ao facto de serem caloiros, ao início de uma nova fase das suas vidas, à adaptação a uma nova cidade, novos relacionamentos, por outras palavras, a todo o novo processo de transição. O mesmo sucede com o coping, embora especificamente algumas estratégias sejam mais utilizadas pelos alunos do último ano.

Existem pequenas diferenças no stress pela influência do sexo, mas verifica-se que o sexo feminino apresenta maior ansiedade face à avaliação. $\mathrm{O}$ coping também é idêntico para ambos os sexos, no entanto, a maioria das estratégias são mais utilizadas pelo sexo feminino, com a clara excepção do uso de álcool/ drogas e do humor, predominante no sexo masculino. 
O stress apresenta uma tendência para ser inferior para o nível sócioeconómico intermédio, mas o coping e a grande maioria das respectivas estratégias são superiores para o nível sócio-económico mais baixo, no entanto, a influência apenas é significativa para o uso de álcool/ drogas, este mais utilizado pelo nível sócio-económico mais alto.

Relativamente à idade, ela influencia apenas o factor de stress ansiedade social, que diminui com o aumento da idade e as estratégias de coping apoio social instrumental e uso de álcool/ drogas, cuja utilização diminui com o aumento da idade.

O stress apresenta uma relação positiva com o coping, pelo que podemos concluir que este surge como resposta ao stress, não se verificando a diminuição dos níveis de stress com o aumento da utilização das estratégias de coping, como seria talvez de esperar. Especificamente, as estratégias inibição de coping e apoio na religião surgem como resposta ao factor de stress associado às condições sócioeconómicas; a focagem de emoções, desinvestimento mental, negação, desinvestimento comportamental são as estratégias mais utilizadas como resposta aos vários factores de stress. 


\section{FONTES E BIBLIOGRAFIA}

CARVER, C.S.; SCHEIER, M.F.; WEINTRAUB, J.K. (1989). Assessing coping strategies: A theoretically based approach. Journal of Personality and Social Psychology, 45, 267-283.

COMPAS, B. (1987). Coping with stress during childhood and adolescence. Psychological Bulletin, 101, 393-403

FERRAZ, M.; PEREIRA, A. (2002). A dinâmica da personalidade e o homesickness (saudades de casa) dos jovens estudantes universitários. Psicologia, saúde \& doenças, vol.3, no.2, p.149-164

FERREIRA, Susana. (2006). Stress e coping em estudantes universitários. Dissertação apresentada à Universidade Católica Portuguesa para a obtenção do grau de mestre em ciências da educação - especialização em aprendizagem e desenvolvimento psicológico.

FOLKMAN, S., \& LAZARUS, R. (1985). If it changes it must be a process: A study of emotion and coping during three stages of a college examination. $J$ Pers Soc Psychol. Jan; 48 (1):150-70.

FOLKMAN, S., \& LAZARUS, R. (1988). Manual for the ways of coping questionnaire. California: Consulting Psychologists Press.

FOLKMAN, S., \& MOSKOWITZ, J. T. (2000). Positive affect and the other side of coping. American Psychologist, Jun; 55 (6), 647-54

FOLKMAN, S., \& MOSKOWITZ, J. T. (2000). Stress, positive emotion and coping. Current Directions in Psycological Science, Volume 9, Number 4, August, pp. 115-118(4)

FONSECA, A. (2005). Desenvolvimento humano e envelhecimento. Lisboa: Climepsi Editores.

GARSON, D. G. (2006). Reliability Analysis. Disponível em http://www2.chass.ncsu.edu/garson/pa765/reliab.htm (Consulta realizada a 15.06.2008).

LAZARUS, R. (1999). Stress and emotion. Free Association Books.

LAZARUS, R. (2000). Toward better research on stress and coping. American Psycologist, 55, pp. 665-673.

LAZARUS, R., \& FOLKMAN, S. (1984). Stress, appraisal and coping. New York: Sringer.

MAROCO, João (2003), Análise Estatística - Com Utilização do SPSS. Edições Sílabo, Lisboa.

PEREIRA, Anabela M. S., MOTTA, Elisa Decq, VAZ, António Luzio et al. (2006). Sucesso e desenvolvimento psicológico no Ensino Superior: Estratégias de intervenção. Análise Psicológica, Jan., vol.24, no.1, p.51-59. 
PESTANA, Maria Helena; GAGEIRO; João Nuno (2005). Análise de dados para Ciências Sociais - A complementaridade do SPSS. 4. ${ }^{a}$ Ed. Rev. e aumentada, Edições Sílabo, Lisboa.

PINTO, A. M., MARTíNEZ, I. M. M., \& SILVA, A. L. (2000). Burnout em estudantes do ensino superior. Revista Portuguesa de Psicologia, 35, 151167.

PRANG, Herman; KLOET, Ron; OS, Jim (2005). Stress, o Cérebro e a Depressão. Lisboa, Climepsi Editores.

SELYE, H. (1991). History and present status of the stress concept. In, A. Monat $\&$ R. Lazarus (Eds.), Stress and coping: an anthology. New York: Columbia University Press.

SERRA, A. Vaz (1988). Um estudo sobre coping: o "inventário de resolução de problemas". Psiquiatria clínica, Vol. 9, n. ${ }^{\circ} 4,301-316$.

SERRA, A. Vaz, FIRMINO, H., \& RAMALHEIRA, C. (1988). Estratégias de coping e auto-conceito. Psiquiatria clínica, Vol. 9, nº 4, p.317-322.

SERRA, A. Vaz (2002). O stress na vida de todos os dias. 2. ${ }^{a}$ Edição, Coimbra: Adriano Vaz Serra.

YAFFEE, R. A. (1999). Common Correlation and Reliability Analysis with SPSS for Windows. New York University. Disponível em http://www.nyu.edu/its/statistics/Docs/correlate.html (Consulta realizada a 15.06.2008). 


\section{ANEXO - QUESTIONÁRIO}

\section{Universidade Católica Portuguesa \\ Centro Regional das Beiras \\ Pólo de Viseu}

\section{Questionário sobre os Níveis de Stress da Comunidade Académica da Universidade Católica Portuguesa - Pólo de Viseu}

Trabalho de Investigação integrado na Cadeira de Investigação em Serviço Social, a ser realizado por: Bruno Costa, Fábio Lopes e Mauro Neves, alunos do $3^{\circ}$ ano da Licenciatura em Serviço Social.

Este questionário é dividido em duas partes, na primeira pretende-se identificar quais os principais factores indutores de Stress em contexto Universitário na segunda perceber como os mesmos estudantes lidam com o Stress. Estes dados são absolutamente confidenciais e a tua participação é muito importante. Responde a todos os itens com sinceridade.

Sexo: Feminino.... $\square$ Masculino....

Idade:

Curso: Arquitectura.......... Gestão...........

Medicina Dentaria...

Ano: $1^{\circ}$ Ano.... $\square$ Finalista...

Habilitações literárias do Pai:

Ensino Primário $\left(1^{\circ}\right.$ ao $4^{\circ}$ ano $) \ldots . . . . \square$ Ensino Básico $\left(5^{\circ}\right.$ ao $9^{\circ}$ ano $) \ldots \square$

Ensino Secundário $\left(10^{\circ}\right.$ ao $12^{\circ}$ ano)... Ensino Superior..................

Habilitações literárias da Mãe:

Ensino Primário $\left(1^{\circ}\right.$ ao $4^{\circ}$ ano $) \ldots . . . . \square$ Ensino Básico $\left(5^{\circ}\right.$ ao $9^{\circ}$ ano $) \ldots . \square$

Ensino Secundário $\left(10^{\circ}\right.$ ao $12^{\circ}$ ano $) . . \square$ Ensino Superior.................

Quais os rendimentos do Agregado Familiar:

0 a $500 € . . \square 501 €$ a $1000 €$.. $\square 1001 €$ a $1500 €$.. $\square$ Superior a $1500 €$.. 


\section{Identificação dos factores de stress em Estudantes Universitários}

(Anabela Pereira e Equipa do GAP_SASUC, 2003)

Respostas entre 1 mínimo (discordância total) e 5 máximo (concordância total).

\begin{tabular}{|c|c|c|c|c|c|c|}
\hline & & 1 & 2 & 3 & 4 & 5 \\
\hline 1 & Habitualmente ando muito stressado(a) & 1 & 2 & 3 & 4 & 5 \\
\hline 2 & A minha adaptação à cidade foi difícil & 1 & 2 & 3 & 4 & 5 \\
\hline 3 & A praxe académica foi desagradável & 1 & 2 & 3 & 4 & 5 \\
\hline 4 & O facto de ter de mudar de casa / partilhar casa perturba-me muito & 1 & 2 & 3 & 4 & 5 \\
\hline 5 & Fico muito ansioso(a) quando tenho provas de avaliação (testes e axames) & 1 & 2 & 3 & 4 & 5 \\
\hline 6 & As orais enervam-me muitíssimo & 1 & 2 & 3 & 4 & 5 \\
\hline 7 & Fico muito ansioso(a) com as minhas notas/classificações & 1 & 2 & 3 & 4 & 5 \\
\hline 8 & Fico bastante transtornado(a) com os trabalhos que os professores mandam para casa & 1 & 2 & 3 & 4 & 5 \\
\hline 9 & Os trabalhos de grupo stressam-me muito & 1 & 2 & 3 & 4 & 5 \\
\hline 10 & $\begin{array}{l}\text { Quando tenho de me relacionar com os meus colegas/amigos sinto-me muito } \\
\text { ansioso(a) }\end{array}$ & 1 & 2 & 3 & 4 & 5 \\
\hline 11 & Quando saio (cinema, café, festas,...) sinto-me stressado(a) & 1 & 2 & 3 & 4 & 5 \\
\hline 12 & Os relacionamentos amorosos perturbam-me muitíssimo & 1 & 2 & 3 & 4 & 5 \\
\hline 13 & Se não tenho boas condições de estudo sinto-me stressado(a) & 1 & 2 & 3 & 4 & 5 \\
\hline 14 & Fico perdido(a) se não tenho material para estudar/trabalhar & 1 & 2 & 3 & 4 & 5 \\
\hline 15 & Cozinhar/preparar refeições inquieta-me imenso & 1 & 2 & 3 & 4 & 5 \\
\hline 16 & Detesto fazer limpezas/arrumações & 1 & 2 & 3 & 4 & 5 \\
\hline 17 & Tenho dificuldades em planificar as minhas actividades & 1 & 2 & 3 & 4 & 5 \\
\hline 18 & Os problemas da minha família provocam-me tensão & 1 & 2 & 3 & 4 & 5 \\
\hline 19 & Os problemas económicos agastam-me muito & 1 & 2 & 3 & 4 & 5 \\
\hline 20 & Tenho dificuldade em definir os meus objectivos & 1 & 2 & 3 & 4 & 5 \\
\hline 21 & Ter de me ligar à internet para fins académicos é uma tarefa que me irrita & 1 & 2 & 3 & 4 & 5 \\
\hline 22 & Não ter computador para fazer trabalhos e pesquisas revolta-me & 1 & 2 & 3 & 4 & 5 \\
\hline 23 & $\begin{array}{l}\text { Quando tenho de falar para um grupo de colegas/professores sinto-me muito } \\
\text { inseguro(a) }\end{array}$ & 1 & 2 & 3 & 4 & 5 \\
\hline 24 & Não gosto de utilizar chats/sms/e-mail para comunicar com pessoas & 1 & 2 & 3 & 4 & 5 \\
\hline 25 & Comer na cantina é para mim uma situação desagradável & 1 & 2 & 3 & 4 & 5 \\
\hline 26 & Deixar tudo para a última da hora deixa-me enervadíssimo(a) & 1 & 2 & 3 & 4 & 5 \\
\hline 27 & Preocupa-me não conseguir arranjar emprego depois de acabar o curso & 1 & 2 & 3 & 4 & 5 \\
\hline 28 & A falta da prática de desporto faz-me andar irritado(a) & 1 & 2 & 3 & 4 & 5 \\
\hline 29 & Os problemas de natureza psicológica faz-me andar irritado(a) & 1 & 2 & 3 & 4 & 5 \\
\hline 30 & Os problemas de saúde física influenciam o meu ritmo de vida universitária & 1 & 2 & 3 & 4 & 5 \\
\hline 31 & A relação que mantenho com a minha família provoca-me instabilidade emocional & 1 & 2 & 3 & 4 & 5 \\
\hline 32 & Perturba-me não ter tempo para fazer tudo o que gostaria/necessito de fazer & 1 & 2 & 3 & 4 & 5 \\
\hline 33 & Ter de utilizar transportes públicos causa-me muita irritação & 1 & 2 & 3 & 4 & 5 \\
\hline 34 & A falta de tempo para estudar põe-me nervoso(a) & 1 & 2 & 3 & 4 & 5 \\
\hline 35 & Ficar parado em filas de trânsito enfurece-me & 1 & 2 & 3 & 4 & 5 \\
\hline 36 & Não ter tempo para mim irrita-me & 1 & 2 & 3 & 4 & 5 \\
\hline 37 & Sentia-me melhor se os prazos para a entrega de trabalhos fossem mais alargados & 1 & 2 & 3 & 4 & 5 \\
\hline 38 & Preferia de não ter de fazer a defesa dos trabalhos finais (projecto/monografias/teses) & 1 & 2 & 3 & 4 & 5 \\
\hline 39 & Fico inibido(a) perante pessoas que conheço mal & 1 & 2 & 3 & 4 & 5 \\
\hline 40 & As situações inesperadas põem-me nervoso(a) & 1 & 2 & 3 & 4 & 5 \\
\hline 41 & Sinto-me mal quando estou sozinho(a) em locais públicos & 1 & 2 & 3 & 4 & 5 \\
\hline 42 & A falta de espaços verdes "sufoca-me" & 1 & 2 & 3 & 4 & 5 \\
\hline 43 & A situação política ou económica provoca-me instabilidade & 1 & 2 & 3 & 4 & 5 \\
\hline 44 & Não ter horário pessoal de estudo, devidamente organizado, provoca-me stress & 1 & 2 & 3 & 4 & 5 \\
\hline 45 & A ruptura de uma relação amorosa deixa-me "muito em baixo" & 1 & 2 & 3 & 4 & 5 \\
\hline 46 & Ter uma auto-estima baixa faz-me sentir inseguro(a) & 1 & 2 & 3 & 4 & 5 \\
\hline 47 & Não gostar do meu corpo provoca-me mal-estar & 1 & 2 & 3 & 4 & 5 \\
\hline 48 & Não ter amigos faz-me sentir muito infeliz & 1 & 2 & 3 & 4 & 5 \\
\hline 49 & Ter de lidar com situações difíceis provoca-me stress & 1 & 2 & 3 & 4 & 5 \\
\hline 50 & A minha falta de motivação para estudar preocupa-me muito & 1 & 2 & 3 & 4 & 5 \\
\hline
\end{tabular}




\section{Lidar com o Stress}

(Carver, C.S. \& Scheier, M.F. 1995; tradução de Marques Pinto, A. 2000)

1- Habitualmente não faço isto de todo, 2- Habitualmente faço um pouco isto,

3- Habitualmente faço isto moderadamente, 4- Habitualmente faço muito isto

\begin{tabular}{|c|c|c|c|c|c|}
\hline 1 & Tento crescer como pessoa, como resultado dessa experiência & 1 & 2 & 3 & 4 \\
\hline 2 & Volto-me para o trabalho ou outras actividades substitutas, para não pensar nas coisas & 1 & 2 & 3 & 4 \\
\hline 3 & Fico perturbado(a) e exprimo as minhas emoções & 1 & 2 & 3 & 4 \\
\hline 4 & Procuro obter conselho de alguém sobre o que fazer & 1 & 2 & 3 & 4 \\
\hline 5 & Concentro os meus esforços em fazer qualquer coisa quanto a isso & 1 & 2 & 3 & 4 \\
\hline 6 & Digo a mim próprio(a) "isto não está a acontecer" & 1 & 2 & 3 & 4 \\
\hline 7 & Confio-me a Deus & 1 & 2 & 3 & 4 \\
\hline 8 & Rio-me da situação & 1 & 2 & 3 & 4 \\
\hline 9 & Admito perante mim mesmo(a) que não posso lidar com a situação, e desisto de tentar fazê-lo & 1 & 2 & 3 & 4 \\
\hline 10 & Controlo-me para não fazer qualquer coisa precipitada & 1 & 2 & 3 & 4 \\
\hline 11 & Discuto os meus sentimentos com alguém & 1 & 2 & 3 & 4 \\
\hline 12 & Uso álcool ou drogas para me fazer sentir melhor & 1 & 2 & 3 & 4 \\
\hline 13 & Habituo-me à ideia de que isso aconteceu & 1 & 2 & 3 & 4 \\
\hline 14 & Falo com alguém para me informar melhor sobre a situação & 1 & 2 & 3 & 4 \\
\hline 15 & Evito distrair-me com outros pensamentos ou actividades & 1 & 2 & 3 & 4 \\
\hline 16 & Sonho acordado(a) com outras coisas & 1 & 2 & 3 & 4 \\
\hline 17 & Fico perturbado(a) e tenho plena consciência disso & 1 & 2 & 3 & 4 \\
\hline 18 & Procuro a ajuda de Deus & 1 & 2 & 3 & 4 \\
\hline 19 & Faço um plano de acção & 1 & 2 & 3 & 4 \\
\hline 20 & Digo piadas sobre o assunto & 1 & 2 & 3 & 4 \\
\hline 21 & Aceito que isso aconteceu e não pode ser alterado & 1 & 2 & 3 & 4 \\
\hline 22 & Evito fazer qualquer coisa quanto a isso até que a situação o permita & 1 & 2 & 3 & 4 \\
\hline 23 & Procuro obter apoio emocional de amigos e família & 1 & 2 & 3 & 4 \\
\hline 24 & Simplesmente desisto de tentar atingir esse objectivo & 1 & 2 & 3 & 4 \\
\hline 25 & Faço tentativas adicionais para tentar libertar-me do problema & 1 & 2 & 3 & 4 \\
\hline 26 & Tento descontrair-me por um bocado, bebendo álcool ou tomando drogas & 1 & 2 & 3 & 4 \\
\hline 27 & Recuso-me acreditar que isso aconteceu & 1 & 2 & 3 & 4 \\
\hline 28 & Exprimo os meus sentimentos & 1 & 2 & 3 & 4 \\
\hline 29 & Tento ver as coisas de outra perspectiva para que pareçam mais positivas & 1 & 2 & 3 & 4 \\
\hline 30 & Falo com alguém que possa fazer algo de concreto quanto ao problema & 1 & 2 & 3 & 4 \\
\hline 31 & Durmo mais do que o habitual & 1 & 2 & 3 & 4 \\
\hline 32 & Tento definir uma estratégia sobre o que fazer & 1 & 2 & 3 & 4 \\
\hline 33 & Concentro-me na resolução do problema e, se necessário, deixo as outras coisas um pouco de lado & 1 & 2 & 3 & 4 \\
\hline 34 & Procuro simpatia e compreensão de alguém & 1 & 2 & 3 & 4 \\
\hline 35 & Bebo álcool ou tomo drogas para pensar menos nisso & 1 & 2 & 3 & 4 \\
\hline 36 & Brinco com o assunto & 1 & 2 & 3 & 4 \\
\hline 37 & Desisto de tentar obter o que quero & 1 & 2 & 3 & 4 \\
\hline 38 & Procuro encontrar algo de bom no que está a acontecer & 1 & 2 & 3 & 4 \\
\hline 39 & Penso como poderia lidar com o problema da melhor maneira & 1 & $\frac{2}{2}$ & 3 & 4 \\
\hline 40 & Finjo que isso não aconteceu & 1 & 2 & 3 & 4 \\
\hline 41 & Asseguro-me de que não vou piorar as coisas por agir demasiado cedo & 1 & 2 & 3 & 4 \\
\hline 42 & Tento seriam/ evitar que outras coisas interfiram com os meus esforços para lidar com a situação & 1 & 2 & 3 & 4 \\
\hline 43 & Vou ao cinema ou vejo televisão para pensar menos nisso & 1 & 2 & 3 & 4 \\
\hline 44 & Aceito a realidade do facto de que isso aconteceu & 1 & 2 & 3 & 4 \\
\hline 45 & Pergunto a pessoas que tiveram experiências semelhantes o que fizeram & 1 & 2 & 3 & 4 \\
\hline 46 & Sinto muita perturbação emocional e dou comigo a exprimir fortemente esses sentimentos & 1 & 2 & 3 & 4 \\
\hline 47 & Tomo medidas directas para superar o problema & 1 & 2 & 3 & 4 \\
\hline 48 & Procuro encontrar conforto na minha religião & 1 & 2 & 3 & 4 \\
\hline 49 & Forço-me a esperar pela altura certa para fazer alguma coisa & 1 & 2 & 3 & 4 \\
\hline 50 & Faço troça da situação & 1 & 2 & 3 & 4 \\
\hline 51 & Reduzo o grau de esforço que estou a pôr na resolução do problema & 1 & 2 & 3 & 4 \\
\hline 52 & Falo com alguém sobre como me sinto & 1 & 2 & 3 & 4 \\
\hline 53 & Uso álcool ou drogas para me ajudar a atravessar a situação & 1 & 2 & 3 & 4 \\
\hline 54 & Aprendo a viver com isso & 1 & 2 & 3 & 4 \\
\hline 55 & Ponho de lado outras actividades para me concentrar no assunto & 1 & 2 & 3 & 4 \\
\hline 56 & Peno muito nos passos a dar & 1 & 2 & 3 & 4 \\
\hline 57 & Ajo como se isso nem sequer tivesse acontecido & 1 & 2 & 3 & 4 \\
\hline 58 & Faço o que tem de ser feito, um passo de cada vez & 1 & 2 & 3 & 4 \\
\hline 59 & Aprendo alguma coisa com a experiência & 1 & 2 & 3 & 4 \\
\hline 60 & Rezo mais do que o habitual & 1 & 2 & 3 & 4 \\
\hline
\end{tabular}

